\title{
Restricting Shuttling in Bis(imidazolium)...Pillar[5]arene Rotaxanes Using Metal Coordination
}

Philipp Langer, ${ }^{[a]}$ Lixu Yang, $^{[a]}$ Constance R. Pfeiffer, ${ }^{[a]}$ William Lewis ${ }^{[a]}$ and Neil R. Champness ${ }^{*[a]}$

School of Chemistry, University of Nottingham, University Park, Nottingham, NG7 2RD, UK E-mail: Neil.Champness@nottingham.ac.uk

\begin{abstract}
Metal coordination to a series of bis(imidazolium)...pillar[5] arene [2]rotaxanes through the formation of metal-carbene bonds facilitates a new strategy to restrict the shuttling motion in [2] rotaxanes. Whereas the pillar[5]arene macrocycle rapidly shuttles along the full length of the bis(imidazolium) rod for the parent [2] rotaxane, $\mathrm{Ag}(\mathrm{I})$ coordination to the imidazolium groups through the formation of $\mathrm{N}$-heterocyclic carbenes leads to restricted motion, effectively confining the shuttling motion of the [2]rotaxane. The $\mathrm{Ag}(\mathrm{I})$ coordinated [2] rotaxanes can be reacted further, either removing the Agcarbene species to recreate the parent [2]rotaxane, or reaction with more bulky $\mathrm{Pd}(\mathrm{II})$ species to further restrict the shuttling motion through steric inhibition.
\end{abstract}

\section{Introduction}

The importance of molecular machines has been well established. Over the past two decades the synthesis of mechanically-interlocked molecules (MIMs) has exceeded mere curiosity and has become a field of increasing significance in both understanding and mimicking key biological processes. Catenanes and rotaxanes are at the forefront of the field ${ }^{[1]}$ with applications in molecular switches, ${ }^{[2]}$ molecular sensing, ${ }^{[3]}$ drug delivery ${ }^{[4]}$ and molecular electronic devices. ${ }^{[5]}$ With molecular machines and switches, a conformational or configurational change occurs as a consequence of applying an external stimulus. Reported stimuli include light, ${ }^{[6]}$ electrochemistry, ${ }^{[7]} \mathrm{pH}^{[8]}$ heat, ${ }^{[9]}$ solvent polarity, ${ }^{[10]}$ cation/anion binding, ${ }^{[11]}$ allosteric effects ${ }^{[12]}$ and reversible covalent bond formation. ${ }^{[13]}$ The coordination of metals has a rich history in catenane and rotaxane synthesis due to their role in early template-based synthetic routes. Additionally, macrocycles have been shown to shuttle from one ligand/binding site to another along a rotaxane rod upon metal exchange, ${ }^{[14]}$ redox processes ${ }^{[15]}$ or protonation ${ }^{[16]}$. The stimuli can affect either the dumbbell rod or the macrocycle that it threads. An 
important feature of such systems is the shuttling of the macrocyclic component on the rod and understanding and controlling this shuttling process is one of the most important themes of the field.

Herein we report a series of [2]rotaxanes composed of a decamethylpillar[5]arene (heretofore simply termed pillar[5]arene) and bis-imidazolium rods of varying lengths prepared in high yields. Pillar[n]arenes are a relatively new class of macrocycles ${ }^{[17]}$ which are highly symmetrical, rigid, tubular-shaped structures. Pillar[5]arenes have received growing interest and have been employed in a variety of applications. ${ }^{[17-22]}$ Pillar[n]arenes, $n=5-10$, are known, however pillar[5]arene ${ }^{[17]}$ has gained increased popularity over the others, in part, due to its facile synthesis and wide availability. Pillar[5]arenes possess electron rich cavities which give rise to selective hostguest chemistry with both positively and neutrally charged electron accepting molecules such as pyridinium and viologen derivatives ${ }^{[18 b, 23]}$ as well as imidazolium, ${ }^{[24]}$ bis(imidazolium) salts, ${ }^{[25]} \mathrm{n}$ alkanes $^{[26]}$ and bis(dicyanobutane). ${ }^{[27]}$ The tubular structure of pillar[n]arenes include two rims which can be selectively ${ }^{[28]}$ or entirely ${ }^{[29]}$ functionalised in order to tune the properties or build supramolecular materials. The rich host-guest chemistry of pillar[n]arenes has been utilised in the synthesis of mechanically interlocked molecules ${ }^{[30-32]}$ and have been applied as molecular shuttles ${ }^{[33]}$ and molecular springs ${ }^{[34]}$. Metals have been used previously in conjunction with pillar[n]arene pseudorotaxanes, ${ }^{[35]}$ but examples are scarce.

In this study we demonstrate that bis(imidazolium)...pillar[5]arene [2] rotaxanes are proligands for $\mathrm{N}$ heterocyclic carbenes (NHCs) and effectively coordinate $\mathrm{Ag}(\mathrm{I})$ and $\mathrm{Pd}(\mathrm{II})$ cations at either end of the rod. The introduction of metal complexes to the rod restricts shuttling motion of the pillar[5]arene along the full length of the [2] rotaxane, providing a simple method of influencing shuttling motion in this class of MIMs.

A series of [2]-rotaxanes 1a-c were synthesised employing rods of varying lengths (Scheme 1). Building blocks bis-imidazole rods, pillar[5]arene, and 2-(iodomethyl)-1,3,5-trimethylbenzene, were each synthesised using one-step procedures (see SI for experimental details). 2-(iodomethyl)-1,3,5trimethylbenzene decomposes in light, therefore the subsequent rotaxane syntheses were performed whilst shielding the reaction from light. [2]Rotaxanes 1a-c were synthesised by dissolving the constituent building blocks in the minimum amount of chloroform required to dissolve all reagents at $-15^{\circ} \mathrm{C}$. Purification of products was achieved employing flash chromatography with yields as high as $84 \%$. Characterisation was completed using ${ }^{1} \mathrm{H},{ }^{13} \mathrm{C}$ and ${ }^{1} \mathrm{H}-{ }^{1} \mathrm{H}$ COSY NMR spectroscopy and highresolution mass spectrometry (HRMS) (see SI). In each case single crystals were obtained by layering hexane onto a chloroform solution of the [2]rotaxane, 1a-c, and their structures confirmed by single 
crystal X-ray diffraction studies (see SI for full details). Despite the possibility of dethreading by dynamic nucleophilic substitution in the presence of an iodo counter anion, rotaxanes 1a-c were bench stable. ${ }^{[36]}$

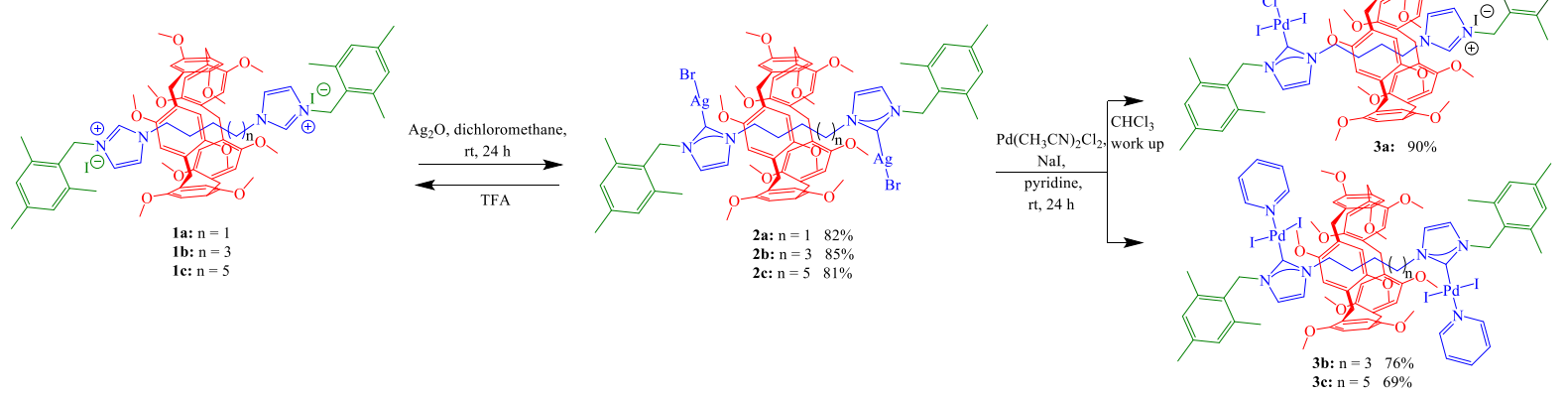

Scheme 1. Metal coordination to the imidazolium salts of rotaxanes $1 \mathrm{a}-\mathrm{c}$ as $\mathrm{N}$-heterocyclic carbenes leads to restriction of the pillar[5]arene shuttling. $\mathrm{Ag}(\mathrm{I})$ coordination can be readily achieved at room temperature and is reversible following addition of acid. $\mathrm{Pd}(\mathrm{II})$ coordination $(\mathbf{3 b}, \mathbf{3 c})$ is readily achieved from the corresponding $\mathrm{Ag}(\mathrm{I})$ complex and in the case of $\mathbf{3 a}$ only a mono-Pd(II) complex is observed due to steric restriction.

It is important to note that the rotaxanes 1a-c behave differently in the solid-state than in solution. The single crystal data for 1a-c shows the pillar[5]arene positioned in the centre of the rod (see SI) and positioned over the linking alkyl chain. The energetics of crystal structures are dominated by intermolecular interactions and efficient packing of molecules, commonly termed packing effects. Although crystal structures reveal the connectivity of a molecule they do not always provide a valuable indication of the molecule's solution-based preferred conformational arrangement. Thus, the crystal structures of the rotaxanes discussed in this study do not necessarily provide a good indication of the solution-phase positioning of the pillar[5]arene with respect to the bis-imidazolium rods.

Indeed, in solution shuttling of the pillar[5]arene with respect to the rod is both anticipated and observed by ${ }^{1} \mathrm{H}$ NMR spectroscopy (Figure 1). Although the whole rod is shielded to some degree, the pillar[5]arene resides preferentially closer to the imidazolium groups at either end of the rod. Neither imidazolium is preferred over the other leaving the pillar[5]arene to shuttle along the length of the rod. Although the alkane chain rod protons $\mathrm{H}_{h-k}$ experience a significant shielding effect, shown by the upfield shift in their NMR peaks, the extent of shielding is not as high as expected if the pillar[5]arene was positioned solely in the centre of the rod (Figure 2). The lack of peak splitting and desymmetrisation suggests that the pillar[5]arene oscillates along the rod faster than the timescale of the NMR experiment. The only exception to this is the signal observed for $\mathrm{H}_{d}$ which is observed as an $A B$ pattern. The protons of the methylene group that links the imidazolium to the stopper group, 
$\mathrm{Hd} / \mathrm{Hd}^{\prime}$, are diastereotopic and non-equivalent due to the chirality of the pillar[5]arene. The chirality transfer observed indicates that the pillar[5]arene is positioned in close proximity to the methylene group despite relatively small upfield shift. Shuttling in rotaxanes has been extensively studied ${ }^{[37-43]}$ including symmetric [2]rotaxanes with two recognition sites separated by alkyl linkers. ${ }^{[37]}$ Although conformational flexibility of alkyl linkers can lead to disruption of shuttling, shorter linkers, such as those described in this study are not anticipated to inhibit fast shuttling processes. ${ }^{[37,38]}$ Thus, the observation of interactions between the pillar[5]arene and the entirety of the rod is consistent with fast shuttling rates. Indeed, the shuttling behaviour was found to be unaffected by temperature within the temperature range studied. VT ${ }^{1} \mathrm{H}$ NMR measurements over a range of temperatures, $293 \mathrm{~K}-$ 193K, exhibited no variation in chemical shifts and only a small broadening of individual peaks (see SI for spectra).

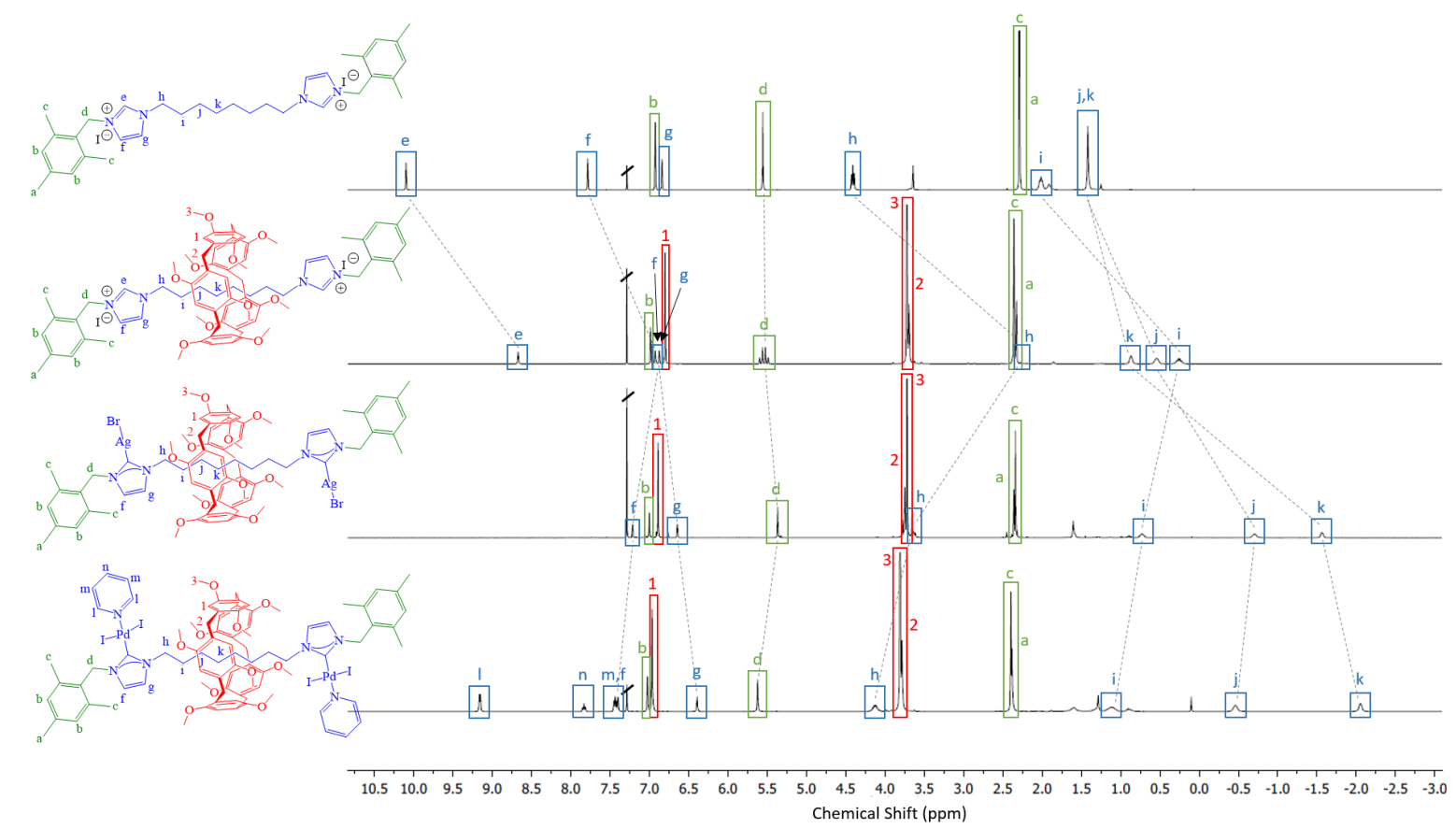

Figure 1. ${ }^{1} \mathrm{H}$ NMR spectra (400 MHz, $\mathrm{CDCl}_{3}, 298 \mathrm{~K}$ ) schematic showing the NMR shifts of $1 \mathrm{c}$ due to the confinement of the pillar[5]arene by the coordination of $\mathrm{Ag}(\mathrm{I}) \mathbf{2 c}$ or $\mathrm{Pd}(\mathrm{II}) 3 \mathrm{3c}$. Bis-imidazolium rod $\mathbf{4 c}$ (top) is included for comparison.

In order to provide a consistent method of comparison we calculated a relative shift for each proton environment [rod ${ }^{1} \mathrm{H}$ chemical shift $(\mathrm{ppm})$ - rotaxane ${ }^{1} \mathrm{H}$ chemical shift $\left.(\mathrm{ppm})\right]$, corresponding to a shielding factor, and then plotted these for each environment along the rod (Figure 2 and SI). The plots contain a mirror plane, reflecting the symmetrical nature of the rotaxanes studied herein. We suggest that a greater shielding factor indicates a greater interaction of the pillar[5]arene, and hence residency over, the given proton environment of the rod. To measure the relative shifts it was required 
to synthesise model compounds for each species without the pillar[5]arene component. Thus, we prepared the analogous bis-imidazolium rods, $4 \mathrm{a}-\mathrm{c}$ (see $\mathrm{SI}$ ), and these were used to calculate the relative shifts. The pillar[5]arene clearly has a greater shielding effect on each end of the rod, rather than the centre of the alkyl linker, in $\mathbf{1} \mathbf{b}$ and $\mathbf{1} \mathbf{c}$. In contrast, the butyl linker in $\mathbf{1 a}$ is sufficiently short such that the imidazolium groups are close enough to maximise binding interactions with the pillar[5]arene without requiring co-conformational motions.

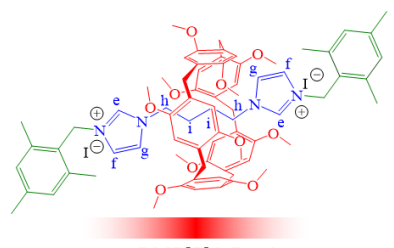

DMP[5]A For 1a

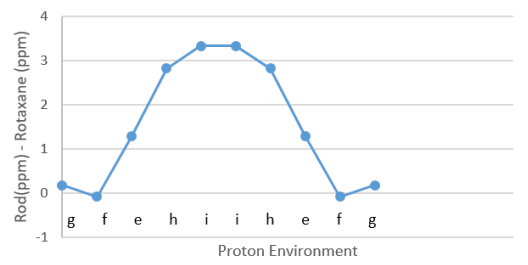

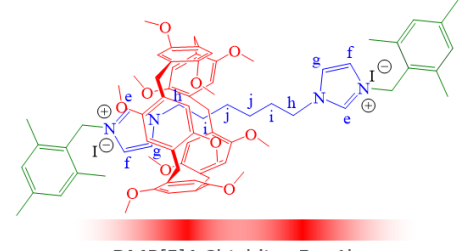

DMP[5]A Shielding For $1 \mathrm{~b}$

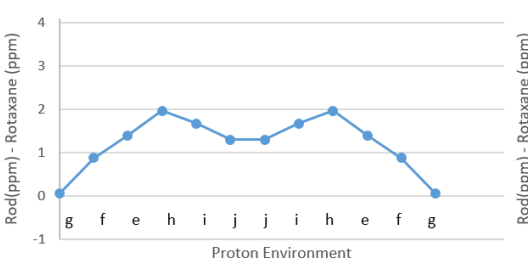

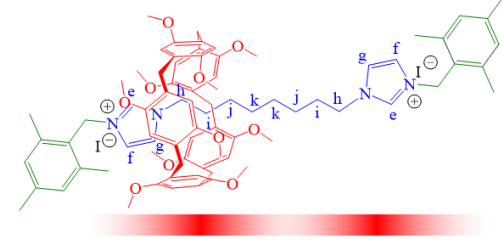

DMP[5]A Shielding For $1 c$

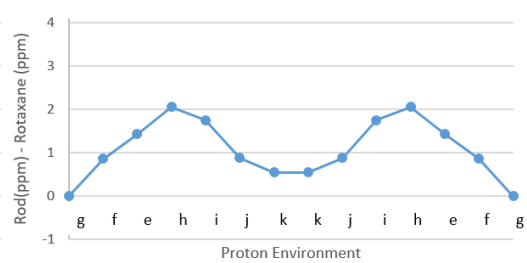

Figure 2. Calculated shielding effects [rod ${ }^{1} \mathrm{H}$ chemical shift $(\mathrm{ppm})$ - rotaxane ${ }^{1} \mathrm{H}$ chemical shift $\left.(\mathrm{ppm})\right]$ for [2]rotaxanes 1a-c indicating the favoured residency of the pillar[5]arene on the rod.

The shielding effect of the pillar[5]arene is solvent dependent as demonstrated by ${ }^{1} \mathrm{H}$ NMR spectra recorded for $1 \mathrm{c}$ (see $\mathrm{SI}$ ). ${ }^{1} \mathrm{H}$ NMR spectra in $\mathrm{CDCl}_{3}$ indicate greater shielding of the rod termini, as discussed above, with the centre of the alkyl chain less affected. Spectra recorded in $\left(\mathrm{CD}_{3}\right)_{2} \mathrm{CO}$ exhibit similar behaviour to those in $\mathrm{CDCl}_{3}$ but in $\left(\mathrm{CD}_{3}\right)_{2} \mathrm{SO}$ larger shielding effects are observed for the central alkyl chain. This suggests that the cationic imidazolium groups are more exposed in the polar $\left(\mathrm{CD}_{3}\right)_{2} \mathrm{SO}$ solvent and is consistent with previous observations in related systems. ${ }^{[33]}$ We also investigated the influence of the counter anion by exchanging iodide for hexafluorophosphate (see SI). In contrast to the effects observed for solvent polarity anion exchange made negligible changes to the shielding effects.

It was anticipated that metal coordination to the imidazolium rings would prevent the free shuttling of the pillar[5]arene along the entirety of the rod and instead confine it to a central position. Thus, a series of metal-coordinated [2] rotaxanes were prepared coordinated to the NHC of the imidazolium salts. The coordination of $\mathrm{Ag}(\mathrm{I})$ to imidazolium salts, as NHCs, is well established. ${ }^{[44]}$ Such $\mathrm{Ag}-\mathrm{NHC}$ coordination occurs at room temperature in dichloromethane and does not require additional reagents (i.e. additional bases). Thus, two equivalents of imidazolium salt were reacted at room 
temperature with one equivalent of $\mathrm{Ag}_{2} \mathrm{O}$ in the presence of $\mathrm{KBr}$ to give $\mathrm{Ag}(\mathrm{I})$ coordinated [2] rotaxanes 2a-c in high yield (see $\mathrm{SI}$ ). Halide scrambling is possible in these systems so an excess of $\mathrm{KBr}$ was added to ensure the formation of bromide complexes. [2]Rotaxanes 2a-c crystallised readily from vapour diffusion of hexane into a solution of the complex in chloroform. Single crystal X-ray diffraction (Figure 3 and $\mathrm{SI}$ ) along with and ${ }^{1} \mathrm{H},{ }^{13} \mathrm{C}$ and ${ }^{1} \mathrm{H}-{ }^{1} \mathrm{H}$ COSY NMR confirmed the structure of the target compounds. To determine the extent of shuttling in $\mathbf{2 a - c}$, in comparison to the nonmetallated [2] rotaxanes 1a-c, ${ }^{1} \mathrm{H}$ NMR spectroscopy was employed to track the position of the pillar[5]arene with respect to the rod. As anticipated the spectrum shows significant shifts in ${ }^{1} \mathrm{H}$ NMR signals (see Figure 1 for representative example of $\mathbf{2 c}$ ) and noticeably so in the signals associated with the alkyl chain. We assessed the shielding effect in $\mathbf{2 a - c}$, using the approach discussed above. This required the synthesis of $\mathrm{Ag}(\mathrm{I})$ complexes of the bis-NHC rods, 5a-c, which were readily prepared from 4a-c using an analogous reaction to those used for the synthesis of $\mathbf{2 a - c}$. Calculation of the shielding effects in $\mathbf{2 a - c}$ clearly indicate that the greatest shift is observed for the protons associated with the alkyl chain linking the metal-binding NHCs. Negligible shifts are observed for the proton environments associated with NHCs, bearing in mind the $\mathrm{Ag}(\mathrm{I})$ coordination to this group. Additionally the protons of the methylene group linking the imidazolium to the stopper group, $\mathrm{H}_{\mathrm{d}}$, no longer exhibit an $A B$ pattern, showing only a sharp singlet, indicating that the pillar[5]arene is no longer in close proximity to these protons and is therefore unable to transfer chirality, as observed for 1a-c. It is clear from these results that the pillar[5]arene is no longer able to shuttle along the full length of the rod in $\mathbf{2 a - c}$ and is therefore confined to the central alkyl chain component of the rotaxane. However, adding a small amount of a proton source, such as trifluoroacetic acid (TFA), the silver coordination can be reversed (see SI) releasing the pillar[5]arene wheel to shuttle freely along the full length of the [2]-rotaxane.

$\mathrm{Ag}(\mathrm{I}) \mathrm{NHCs}$ are known to be reactive and are thus useful starting materials for further functionalisation. ${ }^{[45]}$ Thus, we were able to convert $\mathbf{2 a - c}$ to related $\mathrm{Pd}(\mathrm{II})$ complexes 3a-c at room temperature by reaction with $\mathrm{Pd}\left(\mathrm{CH}_{3} \mathrm{CN}\right)_{2} \mathrm{Cl}_{2}$, Nal and anhydrous pyridine. The resulting complexes contain $\mathrm{Pd}(\mathrm{II})$ bound to the $\mathrm{NHC}$, from the [2]rotaxane, a pyridine ligand, and two iodides. Single crystals were obtained by vapour diffusion (hexane/chloroform solution) and the structures of 3a-c were confirmed by single crystal X-ray diffraction (Figure 3 and $\mathrm{SI}$ ). Whereas the [2] rotaxanes with longer rods, $\mathbf{3 b}$ and $\mathbf{3 c}$, each NHC underwent transmetalation, coordinating $\mathrm{Pd}(\mathrm{II})$ complexes, for $\mathbf{3 a}$ only one of the NHC groups transmetalates with palladium whilst the other was protonated. It is also noticeable that in this instance although we observe Pd-pyridine coordination during the reaction we were only able to isolate a zwitterionic complex in which the $\mathrm{Pd}(\mathrm{II})$ centre is coordinated by the NHC and three halides, two iodides and a chloride. Mono-metalation is a result of the shorter linker between the two imidazolium groups which does not allow two sterically bulky $\operatorname{Pd}($ II) complexes and 
the pillar[5]arene on the same rod. Indeed the presence of the pillar[5]arene can be considered to be controlling the reactivity of the [2] rotaxane and is therefore acting as a protecting group for one of the imidazolium moieties. It is also possible to prepare $\mathbf{3} \mathbf{b}$ and $\mathbf{3} \mathbf{c}$ directly from $\mathbf{1 b}$ and $\mathbf{1} \mathbf{c}$, respectively, through heating solutions of the parent [2]rotaxanes to reflux in pyridine with $\mathrm{Pd}\left(\mathrm{CH}_{3} \mathrm{CN}\right)_{2} \mathrm{Cl}_{2}, \mathrm{Nal}$ and $\mathrm{K}_{2} \mathrm{CO}_{3}$. However this led to noticeably lower overall yields of the $\mathrm{Pd}(\mathrm{II})$ complexes. In the case of the analogous reaction of $1 \mathrm{a}$ the steric bulk and the high reaction temperature led to dethreading of the pillar[5]arene generating a dimetalated $\mathrm{Pd}(\mathrm{II})-$ bis(NHC) species, $6 \mathbf{a}$.

a)

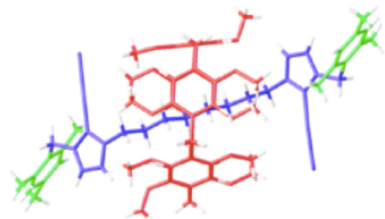

c)

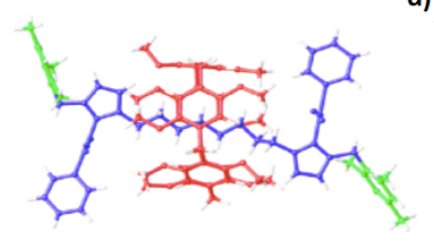

e)

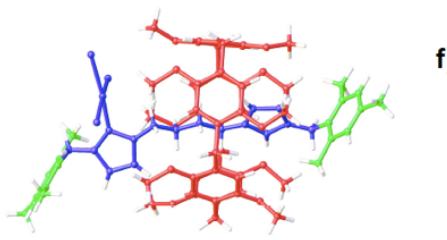

b)

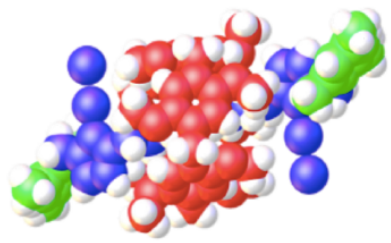

d)

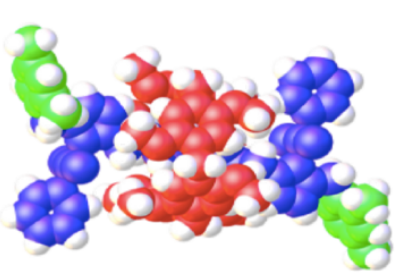

f)

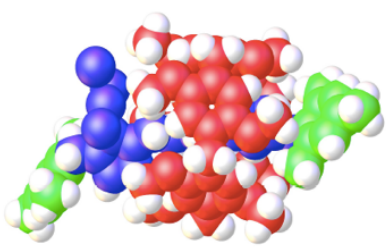

Figure 3. Views of the crystal structures of a, b) 2c; c), d) 3c; e), f) 3a. a), c) and e) ball-and-stick; b), d), f) spacefilled representations. Blue $=$ imidazolium $/ \mathrm{NHC}$ rod, red $=$ pillar[5]arene wheel, and green $=$ mestiyl stopper group.

The shielding effects in 3a-c were evaluated by comparison to a series of $\mathrm{Pd}(\mathrm{II})$ complexes of bis-NHC rods, $6 a-c$, which could be prepared from reaction of $5 a-c$ using analogous conditions to the reactions used for 3a-c (see $\mathrm{SI}$ ). As with the corresponding $\mathrm{Ag}(\mathrm{I})$ complexes, $\mathbf{2 b} / \mathbf{2} \mathbf{c}$, the resulting calculations confirm a significant upfield shift for the ${ }^{1} \mathrm{H}$ shifts associated with the alkyl chain in $3 b / 3 c$ (Figure 4). Due the larger coordination sphere of the $\mathrm{Pd}(\mathrm{II})$ complex the shifts are more pronounced in $\mathbf{3 b} / \mathbf{3 c}$ than $\mathbf{2 b} / \mathbf{2} \mathbf{c}$ indicating more restricted movement of the pillar[5]arene along the [2]rotaxane rod. As with 2a-c, the signal for $\mathrm{H}_{d}$ is observed as a singlet due to the absence of interaction with the pillar[5]arene. 3a behaves quite differently to the other [2] rotaxane complexes due to the asymmetric substitution of the rod, with only one NHC group coordinated to $\mathrm{Pd}(\mathrm{II})$, the other reverting to an imidazolium group. Calculations of the shielding effects clearly indicates this desymmetrisation with the 
pillar[5]arene shifting away from the Pd(II)-NHC complex and deshielding the opposing end of the alkyl chain and the non-coordinated imidazolium group (Figure 4). As anticipated, bearing in mind the discussion above, only one of the methylene proton environments demonstrates chirality transfer from the pillar[5]arene. Chirality transfer is also observed for the protons of the alkyl chain $\left(H_{h}-H_{k}\right)$, in contrast to the symmetrical [2] rotaxanes in this study.

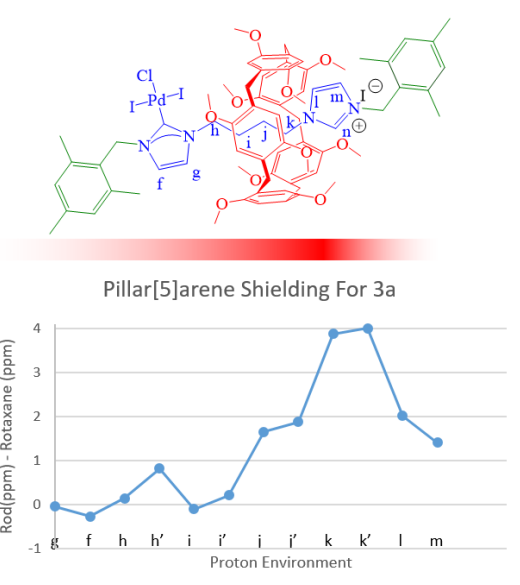

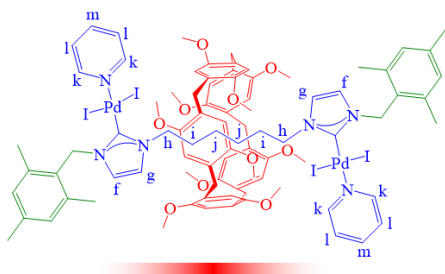

Pillar[5]arene Shielding For 3b

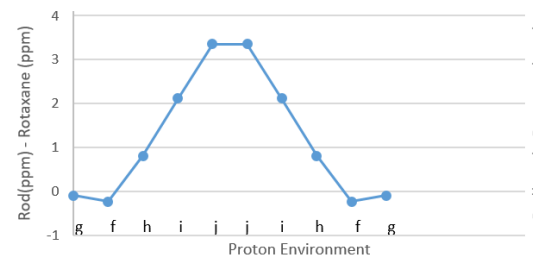

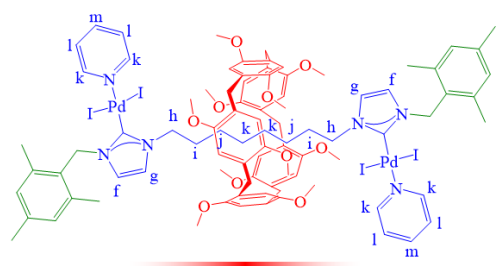

Pillar[5]arene Shielding For 3c

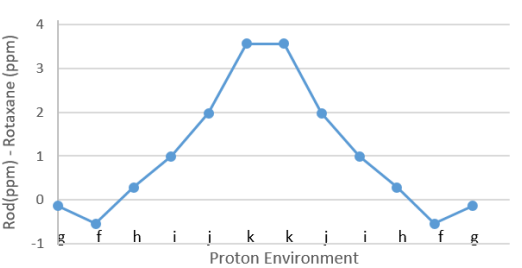

Figure 4. Calculated shielding effects [rod ${ }^{1} \mathrm{H}$ chemical shift $(\mathrm{ppm})$ - rotaxane ${ }^{1} \mathrm{H}$ chemical shift $\left.(\mathrm{ppm})\right]$ for [2]rotaxanes 3a-c indicating the favoured residency of the pillar[5]arene on the rod.

In summary, a high yielding and versatile strategy for the synthesis of rotaxanes based on pillar[5]arene and imidazolium salts has been developed and used to synthesise [2]-rotaxanes with varying rod lengths. It has been demonstrated that the shuttling behaviour of the pillar[5]arene along the full length of the rod can be restricted by coordination of metals, $\mathrm{Ag}(\mathrm{I}), \mathrm{Pd}(\mathrm{II})$, to the imidazolium groups acting as NHCs. Due to the symmetrical metal coordination to these rotaxanes, in all but one case, this process confines the shuttling movement of the pillar[5]arene restricting it to the centre of the rod. We have also demonstrated desymmetrisation of a [2]rotaxane, 3a, which leads to the pillar[5]arene being located asymmetrically on the rod and in the case of $\mathrm{Ag}(\mathrm{I})$ complexes, $\mathbf{2 a - c}$, the metalation process is reversible allowing the release of the confined [2] rotaxane. Our simple strategy represents an approach to influencing and restricting shuttling in these new and potentially diverse class of rotaxanes. Transmetalation of Ag-NHC complexes has been shown to provide a versatile pathway for the coordination of a variety of metals, including $\mathrm{Au}^{\left[{ }^{[46]}\right.} \mathrm{Cu}^{[47]} \mathrm{Fe}^{[47]}$ and $\mathrm{Pd}^{[48]}$, indicating a wide potential variety of target metal-coordinated rotaxane species allowing a mechanism for fine tuning shuttling in these systems.

† Electronic supplementary information (ESI) available: Synthetic Methods, including additional NMR studies and comparison of shielding effects in all [2]rotaxane systems. Additional details of 
crystallographic studies. CCDC 1553404 (1a), 1553406 (1b), 1553407 (1c), 1553408 (2a-Br), 1553411 (2a-Cl), 1553412 (2b), 1553413 (2c), 1860505 (3a), 1553405 (3b), 1553414 (3c), contain the supplementary crystallographic data for this paper. These data can be obtained free of charge from The Cambridge Crystallographic Data Centre via www.ccdc.cam.ac.uk/data_request/cif.

\section{Acknowledgements}

We thank the Engineering and Physical Sciences Research Council (EP/K01773X/1), LY, and the Leverhulme Trust (RPG-2014-317), CRP, for financial support. NRC gratefully acknowledges receipt of a Royal Society Wolfson Merit Award.

\section{References}

[1] a) E. R. Kay, D. A. Leigh and F. Zerbetto, Angew. Chem. Int. Ed. 2007, 46, 72-191; b) C. Cheng, P. R. McGonigal, J. F. Stoddart and R. D. Astumian, ACS Nano. 2015, 9, 8672-8688; c) E. R. Kay and D. A. Leigh, Angew. Chem. Int. Ed., 2015, 54, 10080-10088; d) S. Erbas-Cakmak, D. A. Leigh, C. T. McTernan and A. L. Nussbaumer, Chem. Rev., 2015, 115, 10081-10206; e) C. Cheng and J. F. Stoddart, ChemPhysChem, 2016, 17, 1780-1793; f) V. Marcos, A. J. Stephens, J. Jaramillo-Garcia, A. L. Nussbaumer, S. L. Woltering, A. Valero, J.-F. Lemonnier, I. J. Vitorica-Yrezabal and D. A. Leigh, Science, 2016, 352, 1555.

[2] a) J. M. Spruell, Pure Appl. Chem., 2010, 82, 2281; b) W. Yang, Y. Li, H. Liu, L. Chi and Y. Li, Small, 2012, 8, 504-516.

[3] a) C. G. Collins, E. M. Peck, P. J. Kramer and B. D. Smith, Chem. Sci., 2013, 4, 2557-2563; b) M. J. Langton and P. D. Beer, Acc. Chem. Res., 2014, 47, 1935-1949.

[4] a) C. Moon, Y. M. Kwon, W. K. Lee, Y. J. Park and V. C. Yang, J. Control. Release, 2007, 124, 43-50; b) M. N. Stojanovic and D. Stefanovic, Nat. Biotech. 2003, 21, 1069-1074; c) Z. Li, J. C. Barnes, A. Bosoy, J. F. Stoddart and J. I. Zink, Chem. Soc. Rev., 2012, 41, 2590-2605.

[5] a) C. P. Collier, E. W. Wong, M. Belohradský, F. M. Raymo, J. F. Stoddart, P. J. Kuekes, R. S. Williams and J. R. Heath, Science, 1999, 285, 391; b) C. P. Collier, G. Mattersteig, E. W. Wong, Y. Luo, K. Beverly, J. Sampaio, F. M. Raymo, J. F. Stoddart and J. R. Heath, Science, 2000, 289, 1172; c) A. Coskun, J. M. Spruell, G. Barin, W. R. Dichtel, A. H. Flood, Y. Y. Botros and J. F. Stoddart, Chem. Soc. Rev., 2012, 41, 4827-4859. 
[6] a) P. R. Ashton, R. Ballardini, V. Balzani, A. Credi, K. R. Dress, E. Ishow, C. J. Kleverlaan, O. Kocian, J. A. Preece, N. Spencer, J. F. Stoddart, M. Venturi and S. Wenger, Chem. Eur. J., 2000, 6, 35583574; b) V. Balzani, M. Clemente-León, A. Credi, B. Ferrer, M. Venturi, A. H. Flood and J. F. Stoddart, Proc. Natl. Acad. Sci. (USA), 2006, 103, 1178-1183; c) W. Abraham, L. Grubert, U. W. Grummt and K. Buck, Chem. Eur. J., 2004, 10, 3562-3568.

[7] a) M. Asakawa, P. R. Ashton, V. Balzani, A. Credi, G. Mattersteig, O. A. Matthews, M. Montalti, N. Spencer, J. F. Stoddart and M. Venturi, Chem. Eur. J., 1997, 3, 1992-1996; b) A. Altieri, F. G. Gatti, E. R. Kay, D. A. Leigh, D. Martel, F. Paolucci, A. M. Z. Slawin and J. K. Y. Wong, J. Am. Chem. Soc., $2003,125,8644-8654$.

[8] R. A. Bissell, E. Cordova, A. E. Kaifer and J. F. Stoddart, Nature, 1994, 369, 133-137.

[9] A. Altieri, G. Bottari, F. Dehez, D. A. Leigh, J. K. Y. Wong and F. Zerbetto, Angew. Chem. Int. Ed., $2003,42,2296-2300$.

[10] W. Clegg, C. Gimenez-Saiz, D. A. Leigh, A. Murphy, A. M. Z. Slawin and S. J. Teat, J. Am. Chem. Soc., $1999,121,4124-4129$.

[11] a) S. A. Vignon, T. Jarrosson, T. lijima, H.-R. Tseng, J. K. M. Sanders and J. F. Stoddart, J. Am. Chem. Soc., 2004, 126, 9884-9885; b) D. S. Marlin, D. González Cabrera, D. A. Leigh and A. M. Z. Slawin, Angew. Chem. Int. Ed., 2006, 45, 77-83.

[12] D. S. Marlin, D. González Cabrera, D. A. Leigh and A. M. Z. Slawin, Angew. Chem. Int. Ed., 2006, 45, $1385-1390$

[13] a) A. Altieri, V. Aucagne, R. Carrillo, G. J. Clarkson, D. M. D'Souza, J. A. Dunnett, D. A. Leigh and K. M. Mullen, Chem. Sci., 2011, 2, 1922-1928; b) D. A. Leigh and E. M. Perez, Chem. Commun., 2004, 2262-2263.

[14] a) A. Joosten, Y. Trolez, J.-P. Collin, V. Heitz and J.-P. Sauvage, J. Am. Chem. Soc., 2012, 134, 18021809; b) D. A. Leigh, P. J. Lusby, A. M. Z. Slawin and D. B. Walker, Chem. Commun., 2012, 48, 58265828.

[15] a) N. Armaroli, V. Balzani, J.-P. Collin, P. Gaviña, J.-P. Sauvage and B. Ventura, J. Am. Chem. Soc., 1999, 121, 4397-4408; b) U. Létinois-Halbes, D. Hanss, J. M. Beierle, J.-P. Collin and J.-P. Sauvage, Org. Lett. 2005, 7, 5753-5756. 
[16] J. D. Crowley, D. A. Leigh, P. J. Lusby, R. T. McBurney, L.-E. Perret-Aebi, C. Petzold, A. M. Z. Slawin and M. D. Symes, J. Am. Chem. Soc., 2007, 129, 15085-15090.

[17] a) M. Xue, Y. Yang, X. Chi, Z. Zhang and F. Huang, Acc. Chem. Res., 2012, 45, 1294-1308; b) T. Ogoshi, S. Kanai, S. Fujinami, T.-a. Yamagishi and Y. Nakamoto, J. Am. Chem. Soc., 2008, 130, 5022-5023; c) D. Cao, Y. Kou, J. Liang, Z. Chen, L. Wang and H. Meier, Angew. Chem. Int. Ed., 2009, 48, 9721-9723.

[18] M. Xue, Y. Yang, X. Chi, X. Yan and F. Huang, Chem. Rev., 2015, 115, 7398-7501.

[19] a) W. Xia, X.-Y. Hu, Y. Chen, C. Lin and L. Wang, Chem. Commun., 2013, 49, 5085-5087; b) X. Shu, S. Chen, J. Li, Z. Chen, L. Weng, X. Jia and C. Li, Chem. Commun., 2012, 48, 2967-2969; c) T. Ogoshi, S. Takashima and T.-A. Yamagishi, J. Am. Chem. Soc., 2015, 137, 10962-10964; d) C. Li, X. Shu, J. Li, J. Fan, Z. Chen, L. Weng and X. Jia, Org. Lett., 2012, 14, 4126-4129; e) P. Wang, Z. L and X. Ji, Chem. Commun., 2014, 50, 13114-13116.

[20] a) Y. Fang, L. Wu, J. Liao, L. Chen, Y. Yang, N. Liu, L. He, S. Zou, W. Feng and L. Yuan, RSC Adv., 2013, 3, 12376-12383; b) L.-L. Tan, H. Li, Y. Tao, S. X.-A. Zhang, B. Wang and Y.-W. Yang, Adv. Mater., 2014, 26, 7027-7031; c) T. Ogoshi, R. Sueto, K. Yoshikoshi, Y. Sakata, S. Akine and T.-A. Yamagishi, Angew. Chem. Int. Ed., 2015, 54, 9849-9852.

[21] a) H. Zhang, X. Ma, K. T. Nguyen and Y. Zhao, ACS Nano, 2013, 7, 7853-7863; b) Y. Yao, M. Xue, J. Chen, M. Zhang and F. Huang, J. Am. Chem. Soc., 2012, 134, 15712-15715; c) Q. Duan, Y. Cao, Y. Li, X. Hu, T. Xiao, C. Lin, Y. Pan and L. Wang, J. Am. Chem. Soc., 2013, 135, 10542-10549; d) Y. Chang, K. Yang, P. Wei, S. Huang, Y. Pei, W. Zhao and Z. Pei, Angew. Chem. Int. Ed., 2014, 53, 13126-13130.

[22] a) W. Si, L. Chen, X.-B. Hu, G. Tang, Z. Chen, J.-L. Hou and Z.-T. Li, Angew. Chem. Int. Ed., 2011, 50, 12564-12568; b) X.-B. Hu, Z. Chen, G. Tang, J.-L. Hou and Z.-T. Li, J. Am. Chem. Soc., 2012, 134, 8384-8387; c) L. Chen, W. Si, L. Zhang, G. Tang, Z.-T. Li and J.-L. Hou, J. Am. Chem. Soc., 2013, 135, 2152-2155.

[23] a) C. Li, Q. Xu, J. Li, Y. Feina and X. Jia, Org. Biomol. Chem., 2010, 8, 1568-1576; b) T. Ogoshi, D. Yamafuji, T. Aoki and T.-A. Yamagishi, J. Org. Chem., 2011, 76, 9497-9503; c) T. Ogoshi, R. Shiga and T.-A. Yamagishi, J. Am. Chem. Soc., 2012, 134, 4577-4580. 
[24] a) T. Ogoshi, S. Tanaka, T.-a. Yamagishi and Y. Nakamoto, Chem. Lett. 2010, 40, 96-98; b) W.-B. Hu, W.-J. Hu, X.-L. Zhao, Y. A. Liu, J.-S. Li, B. Jiang and K. Wen, J. Org. Chem., 2016, 81, 3877-3881.

[25] C. Li, L. Zhao, J. Li, X. Ding, S. Chen, Q. Zhang, Y. Yu and X. Jia, Chem. Commun., 2010, 46, 90169018.

[26] T. Ogoshi, K. Demachi, K. Kitajima and T.-A. Yamagishi, Chem. Commun., 2011, 47, 10290-10292.

[27] W.-B. Hu, H.-M. Yang, W.-J. Hu, M.-L. Ma, X.-L. Zhao, X.-Q. Mi, Y. A. Liu, J.-S. Li, B. Jiang and K. Wen, Chem. Commun., 2014, 50, 10460-10463.

[28] a) H. Zhang, N. L. Strutt, R. S. Stoll, H. Li, Z. Zhu and J. F. Stoddart, Chem. Commun., 2011, 47, 11420-11422; b) L. Liu, D. Cao, Y. Jin, H. Tao, Y. Kou and H. Meier, Org. Biomol. Chem., 2011, 9, 7007-7010.

[29] T. Ogoshi, K. Umeda, T.-A. Yamagishi and Y. Nakamoto, Chem. Commun., 2009, 4874-4876.

[30] a) S.-H. Li, H.-Y. Zhang, X. Xu and Y. Liu, Nat. Commun., 2015, 6, 7590; b) W.-B. Hu, W.-J. Hu, X.-L. Zhao, Y. A. Liu, J.-S. Li, B. Jiang and K. Wen, Chem. Commun., 2015, 51, 13882-13885; c) K. Kitajima, T. Ogoshi and T.-A. Yamagishi, Chem. Commun., 2014, 50, 2925-2927.

[31] a) N. L. Strutt, R. S. Forgan, J. M. Spruell, Y. Y. Botros and J. F. Stoddart, J. Am. Chem. Soc., 2011, 133, 5668-5671; b) P. Wei, X. Yan, J. Li, Y. Ma, Y. Yao and F. Huang, Tetrahedron, 2012, 68, $9179-$ 9185; c) S. Dong, C. Han, B. Zheng, M. Zhang and F. Huang, Tetrahedron Lett., 2012, 53, 36683671; d) X.-B. Hu, L. Chen, W. Si, Y. Yu and J.-L. Hou, Chem. Commun., 2011, 47, 4694-4696; e)M. Cheng, Q. Wang, Y. Cao, Y. Pan, Z. Yang, J. Jiang and L. Wang, Tetrahedron Lett., 2016, 57, 41334137.

[32] T. Ogoshi, Y. Nishida, T.-A. Yamagishi and Y. Nakamoto, Macromolecules, 2010, 43, 7068-7072.

[33] a) S. Dong, J. Yuan and F. Huang, Chem. Sci., 2014, 5, 247-252; b) Y. Liu, C. Chipot, X. Shao and W. Cai, J. Phys. Chem. C, 2016, 120, 6287-6293.

[34] Z. Zhang, C. Han, G. Yu and F. Huang, Chem. Sci. 2012, 3, 3026-3031.

[35] X. Wu, Y. Yu, L. Gao, X.-Y. Hu and L. Wang, Org. Chem. Front., 2016, 3, 966-970. 
[36] a) K. Patel, O. S. Miljanic and J. F. Stoddart, Chem. Commun., 2008, 1853-1855; b) O. Š. Miljanić and J. F. Stoddart, Proc. Natl. Acad. Sci. (USA), 2007, 104, 12966-12970.

[37] D. D. Günbas, and A. M. Brouwer, J. Org. Chem., 2012, 77, 5724-5735.

[38] T. Ogoshi, D. Kotera, S. Nishida, T. Kakuta, T. Yamagishi and A.M. Brouwer, Chem. Eur. J. 2018, 24, $6325-6329$.

[39] J. Baggerman, N. Haraszkiewicz, P. G. Wiering, G. Fioravanti, M. Marcaccio, F. Paolucci, E. R. Kay, D. A. Leigh and A. M. Brouwer, Chem.-Eur. J., 2013, 19, 5566

[40] H. Li, Y.-L. Zhao, A. C. Fahrenbach, S.-Y. Kim, W. F. Paxton and J. F. Stoddart, Org. Biomol. Chem., $2011,9,2240-2250$.

[41] M. Hmadeh, A. C. Fahrenbach, S. Basu, A. Trabolsi, D. Benitez, H. Li, A.-M. Albrecht-Gary, M. Elhabiri and J. F. Stoddart, Chem.-Eur. J., 2011, 17, 6076-6087.

[42] P. G. Young, K. Hirose and Y. Tobe, J. Am. Chem. Soc., 2014, 136, 7899-7906.

[43] G. Gholami, K. Zhu, G. Baggi, E. Schott, X. Zarate and S. J. Loeb, Chem. Sci., 2017, 8, 7718-7723.

[44] a) J. M. Hayes, M. Viciano, E. Peris, G. Ujaque and A. Lledós, Organometallics, 2007, 26, 6170$6183 ;$ b) A. A. D. Tulloch, A. A. Danopoulos, S. Winston, S. Kleinhenz and G. Eastham, J. Chem. Soc., Dalton Trans., 2000, 4499-4506.

[45] J.C. Garrison and W.J. Youngs, Chem. Rev. 2005, 105, 3978-4008.

[46] H.-J. Huang, W.-C. Lee, G. P. A. Yap and T.-G. Ong, J. Organomet. Chem., 2014, 761, 64-73.

[47] B. Liu, Y. Zhang, D. Xu and W. Chen, Chem. Commun., 2011, 47, 2883-2885.

[48] Y. Nagai, T. Kochi and K. Nozaki, Organometallics, 2009, 28, 6131-6134. 
Table of Contents Entry:

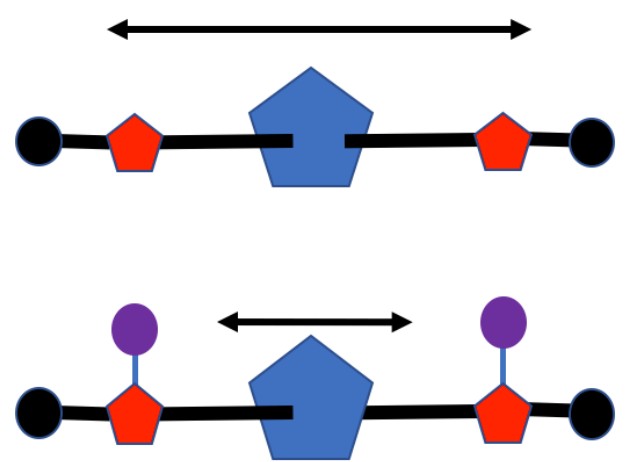

Metal coordination to a series of bis(imidazolium)-pillar[5]arene [2]rotaxanes through the formation of metal-carbene bonds facilitates a new strategy to restrict the shuttling motion in [2]rotaxanes. 